\title{
The Challenge of Disability
}

\author{
SURGEON GENERAL LEROY E. BURNEY
}

$\mathrm{T}$ THE CHALLENGE of disability confronts every physician, whether he is a general practitioner or specialist, in private practice, in medical education, in public health, or in public medical care. It confronts members of all the health professions, as well as public and private welfare agencies. It confronts governments at every level, as well as legislatures.

The burden of disability falls with greatest severity upon disabled individuals, of course, and upon their families. But it affects every citizen, whether as employer, taxpayer, or community leader.

How does our society view disability? There is no doubt that in the United States disability is viewed with compassion, and as a burden which all of us must share with the disabled. Our programs to alleviate the financial burdens of disability and our rehabilitation programs for crippled children and disabled adults are the best evidence of our concern.

But I want to delve deeper into our attitude toward disability. I have observed wide variations in the kinds of services offered to disabled individuals in different countries. The underlying attitude, however, is very much the same. Disability is viewed by all societies as an accomplished fact; an unavoidable burden to be accepted-as our forefathers accepted all disease - as an act of fate or of some malevolent demon.

Dr. Burney, Surgeon General of the Public Health Service, delivered this address at the Governor's Institute on Rehabilitation, Honolulu, Hawaii, January 11, 1960. The paper on page 298, by Dr.T. Nishigaya, who is in private practice in Hawaii, was presented at the same meeting. Dr. Nishigaya's paper also appears in the March-April 1960 issue of the Hawaii Medical Journal.
To be sure, in countries like our own with highly developed medical skills and ample economic resources, there is a strong effort to alleviate disability. But in America and elsewhere we tend to apply the remedy after the factusually too long after. We have yet to develop an attitude which views disability as preventable.

If public health has a particular contribution to make in the field of rehabilitation, I believe that it is to foster an attitude of prevention. Prevention has been the first principle of public health since the birth of the modern movement. The earliest focus of attention, of course, was the prevention and control of infectious diseases. Over the years preventive measures applied by public health agencies and private physicians have averted an inestimable amount of prolonged disability, simply by the control of infections which left many survivors with crippling aftereffects. Many physicians in this audience will recall the frequent heart damage due to diphtheria, syphilis, and rheumatic fever. Most recently, the prevention of paralytic poliomyelitis, through the use of an effective vaccine, is rapidly reducing the accumulation of severely disabled persons due to that cause.

Today, the public health profession as a whole is as much concerned with high disability rates due to chronic conditions as it was with high mortality rates due to diphtheria and typhoid fever 60 years ago. The objective of this concern is to prevent the occurrence of chronic diseases, accidents, and dangerous environmental exposures if possible; if not, to prevent their disabling consequences.

Our Federal-State programs of public health and rehabilitation have one common objective; namely, reduction of the social and economic consequences of disability. Yet there are differ- 
ences in approach. Public health strikes primarily at the causes of disability and hence must seek its opportunities for prevention among supposedly healthy individuals and in the community environment. Rehabilitation strikes primarily at the effects of disability and must seek its opportunities among individuals who are known to be disabled. Both programs are constructive at the core, in that both seek change for the better: change in health status for the whole community, change in the disabled status of the individual.

This determined effort to bring about change is a dynamic force in public health and rehabilitation. It is the force, I believe, which has brought the Public Health Service and the Office of Vocational Rehabilitation into a closer relationship during the past year. We realize more than ever before that our country cannot solve the medical and community service problems involved in disability by piecemeal approaches. Hence we are striving to plan and work together, so that the Service and OVR may more effectively mobilize their resources in a concerted attack on the causes and on the effects of disability.

Disability is a medical problem first and foremost. The success of the attack, therefore, depends primarily upon the alertness and action of each physician. As a social problem, disability can be alleviated by financial support of the disabled, by social services, vocational counseling and training, and placement in employment. It cannot be solved by these means, however, unless everything possible has been done to solve the medical problem.

The preventive approach to disability views the medical solution as beginning the moment a physician sees a patient whose condition obviously or potentially will lead to disability. The medical solution of disability continues as long as the patient needs medical services to sustain his highest potential of active life. This is the central fact which demands a broader view of rehabilitation than has been generally accepted in this country up to the present time. And it is the fact which demands the development of community medical services and the active participation of all physicians.

Rehabilitation services too often are planned around the problems of patients with static con- ditions - the paralytic, the amputee, the blind. Our Federal and State laws related to employee compensation, social insurance, public assistance, and vocational rehabilitation tend to support this view of rehabilitation.

Another handicap to the medical solution of disability is the emphasis on the potential for competitive employment in public and some private rehabilitation programs. This criterion does not take into account the needs of elderly retired persons for rehabilitation services, nor of many severely disabled younger persons who, for one reason or another, do not present a significant potential for employment.

\section{Changes in Community Needs and Services}

The greater efficiency of medicine today warrants a much more flexible response to the challenge of disability. I should like to discuss with you briefly a few of the changes in recent years which focus attention on the role of medicine and public health in rehabilitation.

I need not summon an array of statistics to demonstrate the changes in the patterns of illness. Acute conditions, excluding injuries, account for smaller proportions of the Nation's mortality and prolonged disability. Chronic conditions and severe impairments are the major health problems. There are more older people in the population, and the incidence of chronic conditions increases with age.

Of equal significance, a larger proportion of acutely ill persons survives the initial attack or the injury which first brought them to the physician's attention. Delay in the institution of restorative medical services until the patient's condition has stabilized often means waiting until he has become "permanently and totally disabled."

The initial heart attack, for example, proves with increasing frequency to be the first episode of many. If the physician does not have in mind the prevention of disability from the outset, he may add another "heart cripple" to the increasing number of cardiac patients who are needlessly retired from active life by reason of their disease. Early return to an increasingly active regimen under careful medical supervision will avert many such cases.

There are untold numbers of stroke patients 
surviving today in a tragic sort of half-life. By very simple measures instituted promptly in the home or in the hospital, the majority of stroke patients can recover function within a short period of time. There is ample clinical evidence that more than 80 percent of patients who survive a stroke can become ambulant within two months with appropriate clinical management. The longer the physician waits to institute these measures the longer will the patient be disabled, and the more difficult it will be to restore function.

As the Nation's families and communities struggle with mounting burdens of long-term disability and dependency, are there no alternatives to high-cost care in hospitals and institutions? Fortunately, some States and communities have experimented and found that much disability can be prevented, and that many longterm patients can be cared for in their own homes, often more satisfactorily than in an institution.

The Georgia State Health Department, for example, in cooperation with the State Heart Association, medical organizations, and the Public Health Service is conducting a special program for stroke patients. There are approximately 40,000 survivors of strokes in the State. Often these patients have other serious medical problems and fill hospital beds over long periods of time. Prolonged bed rest, dependency, and speech difficulties generate severe disability, as well as psychological problems in these patients. Their disability creates social and economic difficulties for their families.

The Georgia stroke program includes education of the medical and nursing professions in the early use of physical therapy and early ambulation of stroke patients. A demonstration clinic is being conducted at Grady Memorial Hospital, the teaching hospital of Emory University Medical School. Here the stroke patients are seen on an outpatient basis and appropriate physical therapy is prescribed. The family is responsible for carrying out the therapy in the home. A public health nurse visits the home periodically to instruct the family and to supervise performance of the recommended procedures. A team composed of a physician, a physical therapist, and a public health nurse is available to give intensive training in these procedures to physicians and nurses in local communities.

Another program, even broader in concept than that of the Georgia stroke program, is of interest. This is a home care program for disabled persons conducted in a rural county in North Carolina. It provides medical consultation, nursing, social service, physical and occupational therapy, health and nutrition education, orthopedic equipment, medicines, and sickroom supplies as needed. Residents of the county are eligible regardless of age, sex, or financial status, providing they possess a potential for self-care or self-support. All patients must be referred by a local physician and must remain under his care while receiving services of the program. The Public Health Service is cooperating with State and local agencies in this project.

A specially significant feature of this program, I believe, is its communitywide coverage. So long as community services are restricted to persons dependent on public welfare or to individuals with a potential for employment, medicine and public health will be neglecting the majority of the people needing care. In most rural areas, services such as are provided by this program have to be created. They are not available outside the hospital and many rural hospitals do not have the full range of services required for medical rehabilitation.

I have been told that the first patient to apply for the services of this home care program was a disabled woman whose financial resources are ample to support her for the rest of her life. She wanted to live in her own home rather than in some distant institution. Her inner drive for an active life sought the means for recovery. Her physician could not possibly provide all the services and facilities she needed to achieve this goal. Yet before the community home care program was established, there was no way he could bring the nursing service and special therapies to her bedside.

A few years ago, the Commission on Chronic Illness listed 32 services which patients with long-term conditions are likely to need at various times. While the average physician has his

(Continued on p. 299) 
patient in the hospital, most of these services, plus the basic provision of bed and board, are made available as a matter of course. He takes such services for granted, scarcely realizing that nowhere else in the community will his medical decisions be so scrupulously put into practice. The physician is responsible for making the diagnosis and prescribing the treatment, but an army of professional and ancillary personnel carry out his orders-in the hospital.

These so-called "supplementary services," and the men and women who render them, now play a more important role in the delivery of medical services than the physician himself. In 1900, three in every five professional health workers were physicians; in 1950 , only one in five were physicians. The problem that confronts the physician, as keyman in combating disability, is how to marshal these supplementary services in effective management of his patients - in his office and in their homes.

Public health, with its community-oriented approach, is in a strategic position to help resolve this dilemma of modern medical care. Chronic disease, mental disorders, and the problems of aging may be regarded as the "growing edge" of both prevention and rehabilitation. The benefits from application of the wealth of knowledge in both fields are still largely potential. They will remain largely potential, I fear, until all physicians-in private practice, in administrative positions, and in hospitals-recognize and act upon their responsibilities in these fields. I place this burden on our entire profession for the simple reason that these are medical problems, and the action of other groups in health related services stems from the physician's initiative.

What nurse, for example, will begin the measures which will restore function in a stroke patient-unless the attending physician has specifically prescribed these measures? What personnel manager or supervisor will properly adjust the cardiac patient's work scheduleunless the physician has clearly prescribed the patient's 24-hour schedule of working and living activities? What local health department will allocate its often meager resources to home services for the disabled-unless the medical society endorses such programs, and practicing physicians use the services?

I have tried to present to you this evening some of the changes that are affecting medicine, public health, and rehabilitation. I have shared with you some thoughts on the challenge of disability and how we may meet it with greater confidence. It will not be easy to stimulate a fresh view of disability as a preventable evil. Even with the great scientific advances, the medical solution of disability will not be easy. It is up to us to try.

A first step is for men and women in the fields of medicine, public health, and rehabilitation to get to know each other better. Better understanding of one another's aims, methods, needs, resources, and problems; better communication-these will lead us into better ways of working together for the goals we all want to attain.

Let us also work together for the patient in his community. This means that we must work toward better organization of community services, better balance in our programs, earlier application of preventive methods in the care of all patients. We must do so if our material resources, with a shrinking dollar and a shrinking supply of competent personnel, are to suffice in making a significant impact on disability. 

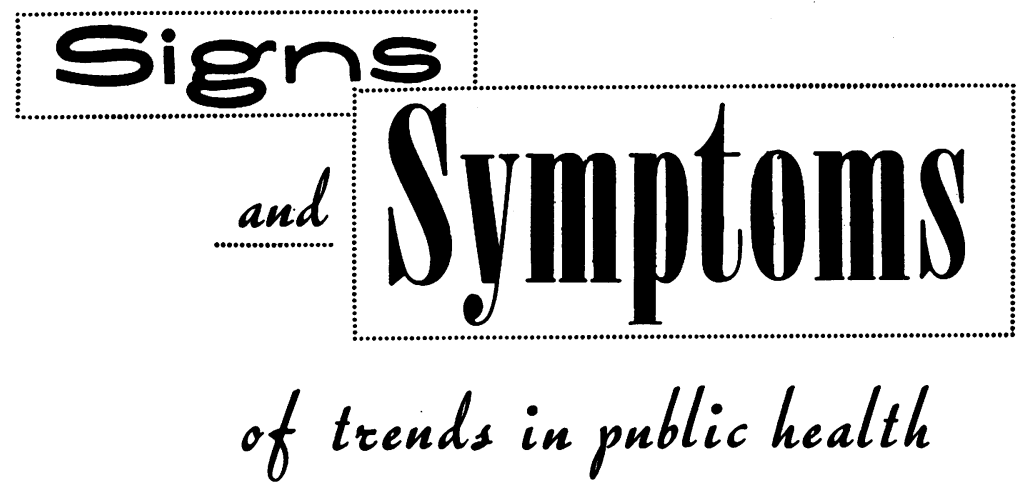

A newly opened $\$ 11 / 2$-million addition to the University of Michigan School of Public Health doubles its teaching and research facilities. Two 4-story wings have been attached to the original building, erected in 1943.

Laboratories for research in epidemiology, industrial and radiological health, and sanitation are being housed in the new wings. In addition, there are multipurpose lecture rooms and workshops, radiation laboratories with lead-lined walls, library facilities, and a 2-story laboratory for testing large equipment.

The new structures, financed in part with funds from the Public Health Service and the Kellogg Foundation, house research equipment valued at one-quarter of a million dollars.

$$
\text { a " }
$$

Accidental release of 3,000 pounds of hexavalent chromium to the Raisin River in Michigan imperiled several municipal water supplies last December. The State Health Department and Water Resources Commission alerted towns to close intakes at water plants as the slug approached. They stayed shut for 12 hours.

$$
\text { 《) }
$$

Chemical and biological research in water, sewage, and industrial wastes at Ohio State University will expand in a new $\$ 180,000$ Water Resources Center, scheduled for completion May 1960.

The facility, now under construction, was financed by a grant from the Public Health Service and State appropriations.
Homemaker Service, a community program administered by the Family Service Association of Greater Boston, has a staff of 110 homemakers who last year served more than 1,200 families. Forty-four homemakers receive a guaranteed annual wage; the others are paid for the amount of time worked. Mrs. Elinor McCabe, the director, and her social workers receive and study all applications and place and supervise the homemakers.

Local departments of public wel. fare in the Greater Boston area purchase this service for selected public assistance families at a rate of $\$ 12.25$ a day. The local department considers this expenditure an administrative expense which is outside the area of Federal financial participation. Through the use of this community service, many public assistance families are able to remain together or continue to live in their own homes when illness or disability occurs.

$$
\text { (<) }
$$

At a cost of more than $\$ 5$ million, the Institute for Muscle Disease has been completed in New York City.

"To increase our knowledge of muscle, to understand the mechanisms by which muscular dystrophy and other muscular disorders arise, and to develop treatments for these conditions," is the primary objective stated by director Dr. Ade T. Milhorat.

$$
\text { ( ) }
$$

In Keene, N.H., 13 cases of typhoid fever were traced to a single lumberman, a carrier, working in the watershed. Chlorination had been suspended.
Per capita health expenditures from tax funds in Connecticut ranged from $\$ 1.20$ to $\$ 2.25$ during 1958 , it is reported in the December 1959 issue of Connecticut Health Bulletin. Broken upon population groups by towns, the statistics show that health expenditure on a per capita basis rises with increase in town population.

Expenditures by individual towns within population groups, however, differ markedly. In towns under 1,000 in population, for example, with an average per capita expenditure of $\$ 1.20$, one town spent 26 cents per capita while another spent $\$ 3$.

$$
\text { 《) }
$$

Quantities of strontium-90 in American water courses sampled weekly by the Public Health Service in 1959 ranged from 0.0 in the first and second quarters at Alsea, Oreg., to an average of 4.8 micromicrocuries per liter in the third quarter at Chattanooga, Tenn. The maximum permissible for lifetime exposure of the general population is 80 . Early readings at Hoover Dam were reported as relatively high but a recheck established a low rating of 0.9 .

$$
\text { u } \gg
$$

Indianapolis was influenced by the etiological relationship bet $\mathbf{w}$ e e $n$ housing and mortality in enacting an up-to-date housing ordinance, as drafted by the committee on the hygiene of housing of the American Public Health Association, according to Dr. Henry J. Nester. He said, "I have found it particularly interesting to note that you have a lower force of mortality in those parishes with higher percentage of houses provided with toilets, baths, and hot and cold running water."

$$
\text { 《) }
$$

Conservation of hearing in Madison County, Miss., is the object of a public program to screen hearing defects among about 9,000 school children, with the use of an audiometer donated by the local Lions Club, which also contributes to the operator's salary.

Funds for the correction of identifled hearing defects in indigent children will be supplied by the Lions Club and the School Health Service. 